\title{
REVIEW
}

\section{The microcirculation of the critically ill pediatric patient}

\author{
Anke PC Top ${ }^{1,2 *}$, Robert C Tasker', Can Ince ${ }^{3}$ \\ This article is one of eleven reviews selected from the Annual Update in Intensive Care and Emergency Medicine 2011 (Springer Verlag) and \\ co-published as a series in Critical Care. Other articles in the series can be found online at http://ccforum.com/series/annual. Further \\ information about the Annual Update in Intensive Care and Emergency Medicine is available from http://www.springer.com/series/8901
}

\section{Introduction}

Hemodynamic monitoring is the cornerstone of critical care, especially when the patient is hemodynamically unstable. It needs to be used with the perspective of tailoring treatment to physiology and the underlying disease process [1]. Monitoring should be easy to apply and negative side effects should be limited. The results should be reliable and reproducible, not least because we also need to monitor response to therapy when cardiovascular insufficiency has been identified. One of the primary goals of hemodynamic monitoring is to alert the physician to impending cardiovascular crisis before organ or tissue injury ensues.

In general, the adequacy of circulatory stability is judged by clinical assessment of parameters that we can measure, e.g., blood pressure, urine output, heart rate and serum lactate concentration. However, these are indirect clinical markers of systemic blood flow and, as such, they are unreliable estimates of overall hemodynamic status during critical illness, irrespective of the experience of the assessing clinician [2,3]. The logic is obvious when one considers that since blood pressure is a regulated variable, a normal blood pressure does not necessarily reflect hemodynamic stability or perturbation [4].

Early recognition of hemodynamic instability in combination with an understanding of the often complex underlying pathophysiology is therefore essential. The clinical art is, first, to monitor the right parameters and, secondly, apply the right target values, which can vary according to age or underlying pathology. In critical illness, these are not necessarily the same as normal

${ }^{*}$ Correspondence: anke.top@addenbrookes.nhs.uk

'Pediatric Intensive Care Unit, Cambridge University NHS Foundation Trust Hospital, Box 7, Hills Road, Cambridge, CB2 0QQ, UK

Full list of author information is available at the end of the article values in health [5]. Pediatric intensivists and anesthesiologists should be familiar with age-appropriate normal values and the physiological differences between adults and children.

\section{Cardiovascular physiology of the pediatric patient}

Differences in growth and development, as well as the pathophysiological response to illness, mean that children cannot be regarded as small adults and data obtained from adults cannot be easily extrapolated to children. Different body proportions, a higher metabolic rate, and lack of compensatory reserve for respiratory or circulatory threats are examples of factors that should influence one's approach to critically ill children. Normal age appropriate values are shown in Table 1.

The cardiovascular system changes markedly at birth due to dramatic alterations in blood flow patterns. Under normal circumstances, the fetal circulation, with its reduced perfusion of the lungs and intra- and extracardiac shunts between the pulmonary and systemic circulations, transitions rapidly to an adult circulation. The precipitous fall in pulmonary vascular resistance and corresponding increase in pulmonary blood flow leads to increased left atrial filling and closing of the intra-atrial connection (foramen ovale). Left ventricular preload rises and the cardiac output increases to meet metabolic demands [6]. In the fetus and newborn, the left ventricle is flattened and the right ventricle is dominant. Newborn babies have less compliant ventricles and therefore have compromised diastolic function. They have a reduced response to inotropes, volume loading, and increased sensitivity to afterload. The immature heart has reduced contractile reserve and a depressed contractile response to exogenous administration of catecholamines.

With the separation of the systemic circulation from the low pressure placental circuit, systemic vascular resistance (SVR) and left ventricular afterload rise steeply 
Table 1. Reference values for heart rate and blood pressure in children [13]. Data are presented as mean and $95 \%$ confidence intervals.

\begin{tabular}{|c|c|c|c|c|}
\hline Age & $\begin{array}{c}\text { Heart rate } \\
\text { [beats/minute] }\end{array}$ & $\begin{array}{l}\text { Mean blood pressure } \\
{[\mathrm{mmHg}]}\end{array}$ & $\begin{array}{l}\text { Systolic blood pressure } \\
{[\mathrm{mmHg}]}\end{array}$ & $\begin{array}{l}\text { Diastolic blood pressure } \\
{[\mathrm{mmHg}]}\end{array}$ \\
\hline Term newborn & $125(70-190)$ & $45(35-60)$ & $70(50-90)$ & $30(20-40)$ \\
\hline 1-11 months & $120(80-160)$ & $60(45-75)$ & $75(55-95)$ & $50(30-70)$ \\
\hline 2 year & $110(80-130)$ & $70(50-90)$ & $90(70-110)$ & $55(40-70)$ \\
\hline 4 year & $100(80-120)$ & $75(50-100)$ & $93(70-115)$ & $56(40-70)$ \\
\hline 6 years & $100(75-115)$ & $75(50-100)$ & $97(80-115)$ & $58(45-75)$ \\
\hline 8 years & $90(70-110)$ & 75 (60-90) & $97(80-115)$ & $58(45-75)$ \\
\hline 10 years & $90(70-110)$ & 75 (60-90) & $103(85-120)$ & $62(47-77)$ \\
\hline 12 years & $85(65-110)$ & 80 (65-95) & $103(85-120)$ & $62(47-77)$ \\
\hline 14 years & $80(60-105)$ & $80(65-95)$ & $110(95-125)$ & $65(50-80)$ \\
\hline
\end{tabular}

in concert with each other. Hence, neonates at birth have little inotropic reserve. They also have reduced preload reserve in comparison with older children and adults. After the transition from fetal to neonatal circulation, the SVR starts to decrease and stroke volumes and cardiac output increase [7]. Stroke volume index (SVI) and cardiac index $(\mathrm{CI})$ continue to increase until the age of 5 years. SVI is stable and CI decreases slightly beyond the age of 5 years. The SVR decreases in the first decade, with the initial major increase followed by a progressive decrease, occurring in the first 48 hours after birth [7]. In infancy and childhood the myocardium adapts progressively to its new loading conditions and develops increased reserve to $\beta$ adrenergic stimulation.

The compensatory mechanisms in hemodynamic disease appear to differ in children compared with adults. Adults with septic shock have decreased ejection fraction and increased cardiac output through ventricular dilatation and increased heart rate [8]. Children with septic shock do not have ventricular dilatation [9]. Therefore, the most important way to increase cardiac output in young children is to increase heart rate. However, there is a problem here. An adult can increase resting heart rate from 60 to 100 beats per minute, but a proportionate increase in an infant from 140 to 220 beats per minute is not sustainable. In adults with septic shock, the hyperdynamic state ('warm shock') is the hallmark of cardiovascular pathophysiology. In children, the response is more heterogeneous [10]. Only a small percentage of children who present with septic shock exhibit a hyperdynamic state, with diminished SVR that responds to vasopressor support without a decrease in CI [10]. The main presentation in pediatric septic shock is a hypodynamic state ('cold shock') with low cardiac output and a high SVR $[11,12]$.

Studies in humans with septic shock suggest that low cardiac output and/or low SVR is detrimental to organ perfusion and survival. Children with septic shock, who maintain a CI between 3.3 and $6.0 \mathrm{l} / \mathrm{min} / \mathrm{m}^{2}$ seem to have a higher survival rate compared to those who have CI outside this range [12].

\section{Hemodynamic monitoring of the pediatric patient}

An important goal of hemodynamic monitoring is to be able to detect inadequate tissue perfusion and oxygenation at an early stage, long before it becomes detrimental. As a consequence, the monitor should prompt and guide resuscitation. Three key components in the physiology of oxygen delivery can be identified:

1. Uptake of oxygen in the lung;

2. Transport and delivery of oxygen from the lung to the tissues; and

3. Oxygen uptake and utilization by the tissues.

At present, available devices for bedside monitoring give limited information about these processes. Oxygen saturation $\left(\mathrm{SO}_{2}\right)$, measured by continuous pulse oximetry $\left(\mathrm{SpO}_{2}\right)$ and arterial blood gas analysis provides information about the oxygen content of the blood $\left(\mathrm{SaO}_{2}\right)$, providing we also know the hemoglobin concentration. This covers oxygen uptake. Oxygen delivery $\left(\mathrm{DO}_{2}\right)$ and utilization are more difficult to assess. $\mathrm{DO}_{2}$ is the product of oxygen content and cardiac output. However, at regional level, vascular resistance is a major factor. There is evidence that low cardiac output is associated with an increased morbidity and mortality [10]. Assessment of cardiac output by means of clinical estimation is inaccurate [3], and invasive measurements are little used in children $[14,15]$. As an alternative to invasive measurement of cardiac output, central $\left(\mathrm{ScvO}_{2}\right)$ or mixed $\left(\mathrm{SvO}_{2}\right)$ venous oxygen saturation has been used as a surrogate for the adequacy of cardiac output in adults. In children with complex congenital heart disease or intra- and/or extracardiac shunts, $\mathrm{SvO}_{2}$ is not a useful measure. Central venous or mixed venous oxygen saturation is also invasive and carries risks in small children. Volumetric indices of cardiac function (e.g., M-Mode, femoral artery 
thermodilution catheter) are used extensively in adult intensive care unit (ICU) in order to derive $\mathrm{DO}_{2}$. However, in the pediatric ICU, intra- and extracardiac shunts may change their validity and relevance. And again, the risks accompanying the insertion of the catheters (e.g., arterial thrombosis) outweigh the potential benefits. Echocardiographic evaluation of cardiac output is not consistently reliable because even in the hands of experienced operators the variation in measurements between and within individuals is large [16]. Taken together, evaluation of cardiac output is much less straightforward in children than it is in adults.

In order to assess tissue perfusion, various measures are followed, including capillary refill time, temperature, and serum lactate concentration. In circulatory failure there is a hierarchy in regional blood flow with diversion away from skin and muscles towards vital organs such as heart, brain, and kidneys. Thus, monitoring skin perfusion could be an early marker of increased sympathetic activity and hypoperfusion. Capillary refill time is a useful clinical parameter during the acute assessment and resuscitation of dehydrated children $[17,18]$. It is non-invasive, easy to use, and cheap. Its use in the pediatric ICU, however, might be of limited value. The correlation with global hemodynamics is poor [19]. Only a weak correlation exists between severely prolonged capillary refill time and SVI and serum lactate concentration [19]. Also, confounding factors such as fever and use of vasoactive medications should be considered. Nonetheless, a dramatic change in this parameter should alert the clinician to the need for a more detailed hemodynamic assessment of the patient.

Lactate metabolism and the prognostic value of high serum lactate concentration in the ICU patient are well documented [20-22]. However, the relationship between lactate and tissue perfusion is not always well defined [23-25], possibly due to the fact that measured lactate is not only the result of the balance between anaerobic production and clearance, but that it may also arise from other sources than hypoxic tissues [26]. Overall these macrocirculatory parameters are currently considered as insensitive markers of tissue perfusion [27]. Ideal hemodynamic monitoring should provide information about whether cells are receiving sufficient oxygen to sustain cellular mitochondrial respiration to produce ATP. Two key elements are the $\mathrm{DO}_{2}$ and the removal of waste products, like carbon dioxide $\left(\mathrm{CO}_{2}\right)$. Important factors that determine $\mathrm{DO}_{2}$ are cardiac output, blood hemoglobin concentration, $\mathrm{SO}_{2}$ of the hemoglobin molecule, and convection and diffusion of oxygen from arterioles to cells. In critical illness, $\mathrm{DO}_{2}$ is often deranged, and many of the common therapeutic interventions in the pediatric ICU (e.g., fluid administration, blood transfusion, inotropes, mechanical ventilation) are, ultimately, used to improve $\mathrm{DO}_{2}$. At present, no real-time monitoring tool for use at the bedside is available for tracking $\mathrm{DO}_{2}$.

\section{The microcirculation as an essential hemodynamic compartment}

Circulatory shock is defined as failure of the cardiovascular system to maintain effective tissue perfusion, causing cellular dysfunction and subsequent acute organ system failure if not restored promptly. Although it is the macrocirculation that distributes blood flow throughout the body, it is the microcirculation that is the critical component of the cardiovascular system ensuring regional blood flow to individual tissues. An optimal macrocirculation, however, is the obvious prerequisite for adequate microcirculatory perfusion. Nevertheless, restoration of global hemodynamics does not always mean that adequate regional tissue perfusion is achieved, especially in conditions of impaired autoregulation, such as occurs during critical illness. Previous studies in adult septic shock patients have shown that indices of microcirculatory blood flow can serve as early indicators of tissue hypoperfusion and therefore provide timely information about the potential onset of multiorgan failure [28-30]. In health, microvascular perfusion is controlled locally so that tissue blood flow and substrate delivery are maintained despite changes in arterial pressure [31]. The lower limit of such flow-autoregulation - from first principles based on mean arterial pressure (MAP) and other factors in Poiseuille's equation - varies between organs, patients, disease state, metabolic activity, and associated vasoactive therapies. Thus, there is no absolute threshold blood pressure that defines adequate organ perfusion among organs, between patients, or in the same patient over time [32]. However, because arterial pressure is a primary determinant of organ blood flow, hypotension is always pathological. Measuring the adequacy of microcirculatory blood flow as a direct indicator of the success of the cardiovascular system to provide adequate oxygen and nutrients to the cells, can be regarded as an important extension of the measurement of systemic hemodynamic variables [33]. However several issues need to be addressed. These are:

1. the reliability and reproducibility of the measurement;

2. the identification of the most relevant microcirculatory parameters which need to be determined; and

3. the prognostic value of these parameters in guiding therapy.

\section{Bedside measurement of the pediatric microcirculation}

The microcirculation plays a crucial role in the interaction between blood and tissue, both in physiological and pathophysiological states. Analysis of alterations in microvascular blood flow therefore provides a unique 
perspective of disease processes at a microscopic level [34]. Orthogonal polarization spectral (OPS) imaging is the first hand-held imaging device that allows bedside visualization of the microcirculation. OPS imaging is based on the optical technique introduced by Slaaf et al. [35], in which green polarized light is used to illuminate the tissue area of interest, which at the bedside is usually the buccal or sublingual mucosa. The green light is absorbed by hemoglobin within the red blood cells (RBCs) in the microcirculation. The reflected light is detected by an orthogonally placed analyzer which filters out surface reflections in order to produce a highcontrast reflected light image of flowing RBCs within the microcirculation [36]. Sidestream darkfield (SDF) imaging is the improved successor to OPS imaging [37] and is based on the dark field illumination technique introduced by Sherman et al. [38]. In this technique, the microcirculation can be observed without the need to use transillumination. Instead SDF imaging uses a stroboscopic lightemitting diode ring-based imaging device so it provides better image quality of the microcirculation [39].

OPS and SDF imaging have been validated in several studies [37,40-44]. Quantification of images is now standardized [45], reproducible, and validated [46]. The parameters that are used to quantify the images include: The microvascular flow index (MFI), a measure of convective flow; the functional capillary density (FCD) or vessel density index (VDI), for diffusion distance; and the heterogeneity index (HI). In the MFI score [46], four different types of flow are recognized and assigned an integer score from 0 to 3: No flow, score 0 ; intermittent flow, score 1; sluggish flow, score 2; and continuous flow, score 3. In order to quantify the microcirculatory flow, each video image is divided into four equal quadrants and the MFI for the whole image is taken as the average score of all quadrants for the different types of vessels, small $(<25 \mu \mathrm{m})$, medium $(26-50 \mu \mathrm{m})$ and large $(51-$ $100 \mu \mathrm{m})$. For the FCD calculation [36], the assessor needs to trace the path of the moving RBCs within the capillaries (i.e., vessels $<10 \mu \mathrm{m}$ ) using a software program (Capiscope version 3.7.1.0, KK Technology 1993-2000). A functional capillary is defined as a capillary that has at least one $\mathrm{RBC}$ moving through it during the observation period. Dividing the length of the perfused capillaries by the area gives the density. In order to calculate the VDI the assessor draws a grid on the computer screen fieldof-view composed of three equidistant horizontal and three equidistant vertical lines. Vessel density is calculated as the number of vessels crossing the lines divided by the total length of the lines. Assessment of the HI [30] involves evaluating three to five mucosal sites and measuring the MFI in each quadrant, taking the difference between highest MFI minus the lowest site MFI, and then dividing the number by the mean flow velocity.
Calculation and measurement of the above parameters has been discussed and agreed upon in a recent consensus conference [45]. It must be noted, however, that analysis and quantification of moving images is cumbersome and time consuming. Although software products do ease and optimize the task [47], no real-time values can be obtained yet. In addition to other technical difficulties (e.g., blurring of the images due to oropharyngeal secretions and artifacts due to movement or pressure) we consider that these microcirculatory imaging techniques, in their present form, are unsuitable for routine clinical use. Nonetheless, the introduction of OPS and SDF imaging to clinical medicine has opened a new field of monitoring during various disease states [48]. The technique is feasible for use in young children [49], providing they have received adequate sedation.

To date, there have been eight studies published on the use of OPS/SDF in children (Table 2). A few studies in newborns and infants have used videophotometric microscopy or laser Doppler to evaluate RBC velocity in the nailfold capillaries of the thumb [50-52]. OPS imaging of the skin has been used in premature and term infants [53-56]. These observations show that the microcirculation in premature infants can be quantified and RBC velocity can be measured. In older children, the most frequently used site for assessment is the buccal mucosa.

\section{The microcirculation in development}

Developmental changes in the structure of the microcirculation occur in the first few weeks of life in healthy neonates and children $[49,55]$. The FCD in the skin of premature infants decreases significantly over the first month of life, which correlates with decreases in hemoglobin concentration and environmental incubator temperature [55]. The FCD of the buccal mucosa also decreases after the first week of neonatal life. It would seem that developmental changes of the microcirculation in early postnatal life are related to adaptation after birth rather than post-conceptional age. It is believed that an adult pattern of microvasculature in the skin is reached by the age of 3 months [61]. An important factor in this development is local cooling. Therefore, it is unclear whether the same would apply for other microvascular beds not directly exposed to environmental temperatures. In the first week of life, compared with birth, there is also the additional 2- to 3-fold increase in oxygen consumption because of increased work of breathing, and increased gastrointestinal function with feeding. Furthermore, high levels of fetal hemoglobin at this time of life reduce the level of oxygen extraction [62]. These factors, taken together, can be compensated by higher systemic and microcirculatory blood flow. The higher FCD in the first week of postnatal life may be related to higher 
Table 2. Pediatric studies of the microcirculation using OPS or SDF imaging

\begin{tabular}{|c|c|c|c|c|c|c|}
\hline Author [ref] & Year & Age range & $\mathbf{n}$ & SDF/OPS & Site & Outcome \\
\hline $\begin{array}{l}\text { Genzel-Boroviczeny } \\
\text { et al. [53] }\end{array}$ & 2002 & $\begin{array}{l}\text { Preterm and term, } \\
1-5 \text { days }\end{array}$ & 28 & OPS & Skin & $\begin{array}{l}\text { Feasibility study: RBC velocity increased from day } 1-5 \text { in } \\
\text { premature neonates and correlated with decrease in hemoglobin }\end{array}$ \\
\hline $\begin{array}{l}\text { Genzel-Boroviczeny } \\
\text { et al. [54] }\end{array}$ & 2004 & Preterm, 19-39 days & 13 & OPS & Skin & FCD improved 2 hours and 24 hours after blood transfusion \\
\hline Kroth et al. [55] & 2008 & Preterm, $0-30$ days & 25 & OPS & Skin & FCD decreased significantly over the first month of life \\
\hline Top et al. [57] & 2009 & Term, $0-18$ days & 14 & OPS & $\begin{array}{l}\text { Buccal } \\
\text { mucosa }\end{array}$ & $\begin{array}{l}\text { FCD was reduced in neonates with severe respiratory failure and } \\
\text { improved following use of veno-arterial extracorporeal } \\
\text { membrane oxygenation }\end{array}$ \\
\hline Weidlich et al. [58] & 2009 & Preterm, $0-30$ days & 10 & OPS & Skin & FCD decreased 1 day before clinical signs of infection appeared \\
\hline Hiedl et al. [56] & 2010 & Preterm, 3-8 days & 25 & SDF & & $\begin{array}{l}\text { Patients with persistent ductus arteriosus had reduced FCD, } \\
\text { which improved after treatment }\end{array}$ \\
\hline Top et al. [49] & 2010 & $0-3$ years & 45 & OPS & $\begin{array}{l}\text { Buccal } \\
\text { mucosa }\end{array}$ & FCD of the buccal mucosa decreased after the first week of life \\
\hline Top et al. [59] & 2010 & $0-15$ years & 21 & OPS & $\begin{array}{l}\text { Buccal } \\
\text { mucosa }\end{array}$ & $\begin{array}{l}\text { Persistence of depressed FCD was associated with a worse } \\
\text { outcome in children with septic shock }\end{array}$ \\
\hline Top et al. [60] & 2010 & $0-3$ years & 8 & OPS & $\begin{array}{l}\text { Buccal } \\
\text { mucosa }\end{array}$ & $\begin{array}{l}\text { Inhaled NO improves the systemic microcirculation in children } \\
\text { with hypoxemic respiratory failure }\end{array}$ \\
\hline
\end{tabular}

OPS: orthogonal polarization spectral imaging; FCD: functional capillary density; RBC: red blood cell; SDF: sidestream darkfield.

cardiac output in the first week [62] and autoreglulation of regional blood flow may have an important role [31].

\section{Microcirculation in disease and the effects of treatment}

Microcirculatory alterations are now considered to be a key hemodynamic property of septic adult patients due to several landmark investigations using OPS and SDF imaging $[27,28,32,64]$. Top and co-workers reported that such alterations also occur in the buccal mucosa of septic children [59]. In premature neonates with sepsis, microcirculatory alterations were observed in the skin using OPS imaging [58]. Furthermore, neonates with severe respiratory failure have depressed microcirculatory parameters [57]. In premature neonates with patent ductus arteriosus (PDA) the FCD of the skin is reduced compared with patients without PDA [56]. The mechanism behind this change is unclear. These patients had left-to-right shunting through the PDA, resulting in reduction of cardiac output (due to blood flow 'leaking' away to the pulmonary circulation). The difference disappeared after closure of the PDA [56]. Microcirculatory alterations can be effectively treated in pediatric patients. Genzel-Boroviczeny et al. observed a direct effect of $\mathrm{RBC}$ transfusion on the microcirculation in premature infants by its ability to increase FCD [54]. Inhaled NO (iNO) improves outcome in infants diagnosed with persistant pulmonary hypertension of the newborn by improving pulmonary blood flow and oxygenation. It reduces pulmonary vascular resistance, without fall in systemic blood pressure. Top et al. [60] showed that iNO improves the microcirculation of the buccal mucosa in children with hypoxemic respiratory failure.

Extracorporeal membrane oxygenation (ECMO) can be considered as a therapy of choice for patients with severe respiratory and circulatory compromise, when conservative treatment fails. Top et al. investigated the microcirculatory response of critically ill pediatric patients to ECMO. They demonstrated that respiratory distress was associated with severe microcirculatory alterations and that after treatment with ECMO, at a time when the patient no longer needed ECMO, the microcirculatory parameters were improved [58].

\section{Prognostic value of the microcirculation}

OPS and SDF have been applied in adults in various clinical settings and have been shown to be associated with the severity of disease and outcome [27,48,63-65], In adult patients with septic shock, microcirculatory parameters that did not resolve after 24 hours of admission, were shown to be associated with poor outcome [27]. The presence of abnormal microcirculatory values has been shown to be correlated with other measures of patient severity of illness during sepsis, such as sequential organ failure assessment (SOFA) scores [63]. Patients who develop nosocomial infection after major abdominal surgery have been shown to exhibit impairment of sublingual microcirculatory parameters [65]. De Backer et al. also found that the degree of microvascular derangement in adults with cardiogenic shock was reflected in their survival [64].

In regards to children, Top et al. found that persistent alterations of the microcirculation were associated with 


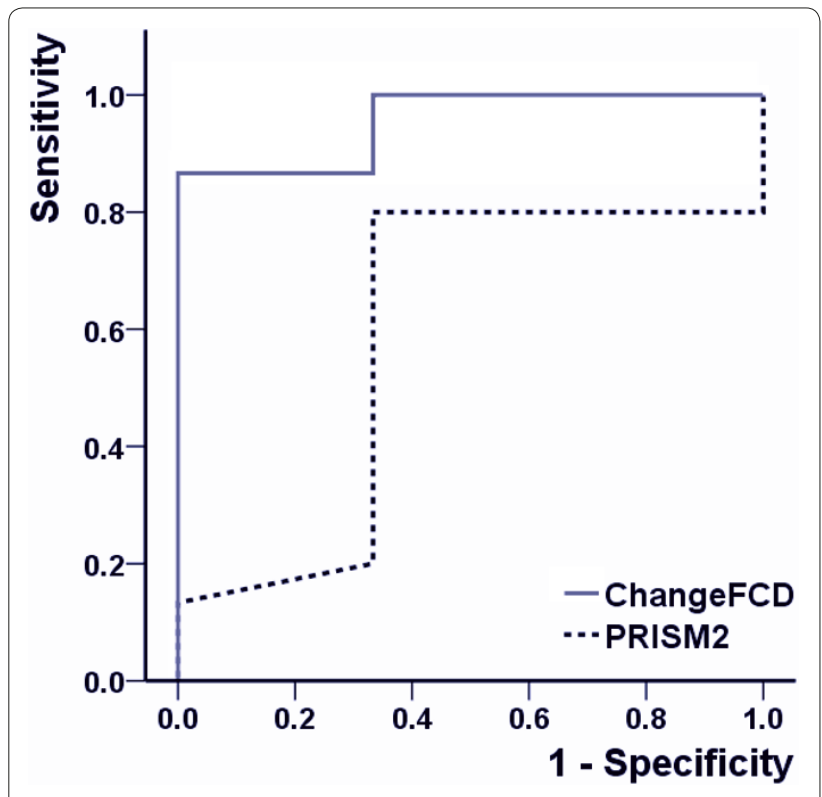

Figure 1. Receiver operator characteristic (ROC) curve for the change in functional capillary density $(\delta F C D)$ within the first 2 days of septic shock in children. The best cut-off is 0.7 . Area under the curve (AUC) for $\delta F C D=0.956(95 \% \mathrm{Cl} 0.853-1.058)$. The ROC curve for pediatric risk of mortality (PRISM) shows a low sensitivity and specificity. It has an AUC of 0.59 (95\%Cl 0.209-0.969) and is significantly less sensitive and specific than the $\delta F C D$ measured by the ROC curve. From [59] with permission.

poor outcome in children with septic shock [59]. Lack of restoration of the altered microcirculation proved to have a stronger predictive value for mortality than severity of illness score using the pediatric risk of mortality (PRISM) model (Fig. 1). In premature neonates, reduction of FCD of the skin can be the first sign of infection. For example, Weidlich et al. observed microcirculatory alterations in premature infants with infection [58]. The authors suggested that these alterations might be predictive of infection, even before clinical suspicion arises.

\section{Conclusion}

Direct observation of the microcirculation is, potentially, a valuable addition to the hemodynamic monitoring of the critically ill pediatric patient, where other monitoring modalities are limited. If the current practical limitations for routine use of OPS and SDF imaging can be overcome, such monitoring modalities may improve outcome by directing clinicians to administer resuscitative therapies in a more timely and effective manner.

\section{Competing interests}

Professor Ince is inventor of SDF imaging technique and as such holds shares in Microvision Medical.

\section{List of abbreviations used}

$\mathrm{Cl}$ : cardiac index; $\mathrm{DO}_{2}$ : oxygen delivery; ECMO: extracorporeal membrane oxygenation; FCD: functional capillary density; $\mathrm{HI}$ : heterogeneity index; iNO: inhaled NO; MAP: mean arterial pressure; MFI: microvascular flow index; OPS: orthogonal polarization spectral; PDA: patent ductus arteriosus; RBC: red blood cell; SDF: sidestream darkfield; $\mathrm{SO}_{2}$ : oxygen saturation; SOFA: sequential organ failure assessment; SVI: stroke volume index; SVR: systemic vascular resistance; VDI: vessel density index.

\section{Author details}

1 Pediatric Intensive Care Unit, Cambridge University NHS Foundation Trust Hospital, Box 7, Hills Road, Cambridge, CB2 0QQ, UK. ²Department of Intensive Care, Erasmus Medical Center-Sophia Children's hospital, Postbox 2040, 3000 CA Rotterdam, Netherlands. ${ }^{3}$ Department of Intensive Care, Erasmus Medical Center, Postbox 2040, 3000 CA Rotterdam, Netherlands.

\section{Published: 22 March 2011}

References

1. Pinsky MR, Payen D: Functional hemodynamic monitoring. Crit Care 2005, 9:566-572.

2. Tibby SM, Hatherill M, Marsh MJ, Murdoch IA: Clinicians' abilities to estimate cardiac index in ventilated children and infants. Arch Dis Child 1997, 77:516-518.

3. Egan JR, Festa M, Cole AD, Nunn GR, Gillis J, Winlaw DS: Clinical assessment of cardiac performance in infants and children following cardiac surgery. Intensive Care Med 2005, 31:568-573.

4. Partrick DA, Bensard DD, Janik JS, Karrer FM: Is hypotension a reliable indicator of blood loss from traumatic injury in children? Am J Surg 2002, 184:555-559.

5. Shoemaker WC, Beez M: Pathophysiology, monitoring, and therapy of shock with organ failure. Appl Cardiopulm Pathophysiol 2010, 14:5-15.

6. Agata Y, Hiraishi S, Misawa H, et al:: Regional blood flow distribution and left ventricular output during early neonatal life: a quantitative ultrasonographic assessment. Pediatr Res 1994, 36:805-810.

7. Cattermole GN, Leung PY, Mak PS, Chan SS, Graham CA, Rainer TH: The normal ranges of cardiovascular parameters in children measured using the Ultrasonic Cardiac Output Monitor. Crit Care Med 2010, 38:1875-1881.

8. Parker MM, Shelhamer JH, Natanson C, Alling DW, Parrillo JE: Serial cardiovascular variables in survivors and nonsurvivors of human septic shock: heart rate as an early predictor of prognosis. Crit Care Med 1987, 15:923-929.

9. Feltes TF, Pignatelli R, Kleinert S, Mariscalco MM: Quantitated left ventricular systolic mechanics in children with septic shock utilizing noninvasive wall-stress analysis. Crit Care Med 1994, 22:1647-1658.

10. Ceneviva G, Paschall JA, Maffei F, Carcillo JA: Hemodynamic support in fluidrefractory pediatric septic shock. Pediatrics 1998, 102:e19.

11. Mercier JC, Beaufils F, Hartmann JF, Azema D: Hemodynamic patterns of meningococcal shock in children. Crit Care Med 1988, 16:27-33.

12. Pollack MM, Fields Al, Ruttimann UE: Distributions of cardiopulmonary variables in pediatric survivors and nonsurvivors of septic shock. Crit Care Med 1985, 13:454-459.

13. Kliegman R: Nelson Textbook of Pediatrics, 18th Edition. Philadelphia: Elsevier; 2007

14. Tibby SM, Murdoch IA: Measurement of cardiac output and tissue perfusion. Curr Opin Pediatr 2002, 14:303-309.

15. Tibby S: Transpulmonary thermodilution: finally, a gold standard for pediatric cardiac output measurement. Pediatr Crit Care Med 2008, 9:341-342.

16. de Boode WP: Cardiac output monitoring in newborns. Early Hum Dev 2010, 86:143-148.

17. Saavedra JM, Harris GD, Li S, Finberg L: Capillary refilling (skin turgor) in the assessment of dehydration. Am J Dis Child 1991, 145:296-298.

18. Mackenzie A, Shann F, Barnes $\mathrm{G}$ : Clinical signs of dehydration in children. Lancet 1989, 2:1529-1530.

19. Tibby SM, Hatherill M, Murdoch IA: Capillary refill and core-peripheral temperature gap as indicators of haemodynamic status in paediatric intensive care patients. Arch Dis Child 1999, 80:163-166.

20. Levy B: Lactate and shock state: the metabolic view. Curr Opin Crit Care 2006, 12:315-321.

21. Fall PJ, Szerlip HM: Lactic acidosis: from sour milk to septic shock. J Intensive Care Med 2005, 20:255-271.

22. Hatherill M, Waggie Z, Purves L, Reynolds L, Argent A: Mortality and the nature of metabolic acidosis in children with shock. Intensive Care Med 
2003, 29:286-291.

23. Marik PE: Sublingual capnometry: a non-invasive measure of microcirculatory dysfunction and tissue hypoxia. Physiol Meas 2006 27:R37-R47.

24. Creteur J, De Backer D, Sakr Y, Koch M, Vincent JL: Sublingual capnometry tracks microcirculatory changes in septic patients. Intensive Care Med 2006, 32:516-523.

25. Fries $M$, Weil MH, Sun S, et al:: Increases in tissue Pco2 during circulatory shock reflect selective decreases in capillary blood flow. Crit Care Med 2006, 34:446-452

26. Levy B, Gibot S, Franck P, Cravoisy A, Bollaert PE: Relation between muscle $\mathrm{Na}+\mathrm{K}+$ ATPase activity and raised lactate concentrations in septic shock: a prospective study. Lancet 2005, 365:871-875.

27. Sakr Y, Dubois MJ, De Backer D, Creteur J, Vincent JL: Persistent microcirculatory alterations are associated with organ failure and death in patients with septic shock. Crit Care Med 2004, 32:1825-1831.

28. Trzeciak S, Rivers EP: Clinical manifestations of disordered microcirculatory perfusion in severe sepsis. Crit Care 2005, 9(Suppl 4):S20-S26.

29. Spronk PE, Zandstra DF, Ince C: Bench-to-bedside review: sepsis is a disease of the microcirculation. Crit Care 2004, 8:462-468.

30. Trzeciak S, Dellinger RP, Parrillo JE, et al:: Early microcirculatory perfusion derangements in patients with severe sepsis and septic shock: relationship to hemodynamics, oxygen transport, and survival. Ann Emerg Med 2007, 49:88-98

31. Guyton AC, Carrier O, Jr., Walker JR: Evidence for Tissue Oxygen Demand as the Major Factor Causing Autoregulation. Circ Res 1964, 15(suppl):60-69.

32. LeDoux D, Astiz ME, Carpati CM, Rackow EC: Effects of perfusion pressure on tissue perfusion in septic shock. Crit Care Med 2000, 28:2729-2732.

33. Weil $\mathrm{MH}$, Tang $\mathrm{W}$ : Welcoming a new era of hemodynamic monitoring: expanding from the macro to the microcirculation. Crit Care Med 2007, 35:1204-1205

34. Fagrell B, Intaglietta M: Microcirculation: its significance in clinical and molecular medicine. J Intern Med 1997, 241:349-362.

35. Slaaf DW, Tangelder GJ, Reneman RS, Jager K, Bollinger A: A versatile incident illuminator for intravital microscopy. Int J Microcirc Clin Exp 1987, 6:391-397.

36. Groner W, Winkelman JW, Harris AG, et al:: Orthogonal polarization spectral imaging: a new method for study of the microcirculation. Nat Med 1999, 5:1209-1212.

37. Goedhart PT, Khalilzada M, Bezemer R, Merza J, Ince C: Sidestream Dark Field (SDF) imaging: a novel stroboscopic LED ring-based imaging modality for clinical assessment of the microcirculation. Opt Express 2007 15:15101-15114.

38. Sherman H, Klausner S, Cook WA: Incident dark-field illumination: a new method for microcirculatory study. Angiology 1971, 22:295-303.

39. Balestra GM, Bezemer R, Boerma EC, et al:: Improvement of sidestream dark field imaging with an image acquisition stabilizer. BMC Med Imaging 2010, 10:15.

40. Harris AG, Sinitsina I, Messmer K: Validation of OPS imaging for microvascular measurements during isovolumic hemodilution and low hematocrits. Am J Physiol Heart Circ Physiol 2002, 282:H1502-H1509.

41. Langer S, Biberthaler P, Harris AG, Steinau HU, Messmer K: In vivo monitoring of microvessels in skin flaps: introduction of a novel technique. Microsurgery 2001, 21:317-324.

42. Langer S, Born F, Hatz R, Biberthaler P, Messmer K: Orthogonal polarization spectral imaging versus intravital fluorescent microscopy for microvascular studies in wounds. Ann Plastic Surg 2002, 48:646-653.

43. Langer S, Harris AG, Biberthaler P, von Dobschuetz E, Messmer K: Orthogonal polarization spectral imaging as a tool for the assessment of hepatic microcirculation: a validation study. Transplantation 2001, 71:1249-1256.

44. Mathura KR, Vollebregt KC, Boer K, De Graaff JC, Ubbink DT, Ince C: Comparison of OPS imaging and conventional capillary microscopy to study the human microcirculation. J App/ Physiol 2001, 91:74-78.

45. De Backer D, Hollenberg S, Boerma C, et al:: How to evaluate the microcirculation: report of a round table conference. Crit Care 2007, 11:R101.

46. Boerma EC, Mathura KR, van der Voort PH, Spronk PE, Ince C: Quantifying bedside-derived imaging of microcirculatory abnormalities in septic patients: a prospective validation study. Crit Care 2005, 9:R601-R606.

47. Dobbe JG, Streekstra GJ, Atasever B, van Zijderveld R, Ince C: Measurement of functional microcirculatory geometry and velocity distributions using automated image analysis. Med Biol Eng Comput 2008, 46:659-670.

48. De Backer D, Creteur J, Preiser JC, Dubois MJ, Vincent JL: Microvascular blood flow is altered in patients with sepsis. Am J Respir Crit Care Med 2002, 166:98-104

49. Top AP, van Dijk M, van Velzen JE, Ince C, Tibboel D: Functional capillary density decreases after the first week of life in term neonates. Neonatology 2010, 99:73-77.

50. Beinder E, Trojan A, Bucher HU, Huch A, Huch R: Control of skin blood flow in pre- and full-term infants. Biol Neonate 1994, 65:7-15.

51. Norman M, Herin P, Fagrell B, Zetterstrom R: Capillary blood cell velocity in full-term infants as determined in skin by videophotometric microscopy. Pediatr Res 1988, 23:585-588.

52. Jahnukainen T, Lindqvist A, Jalonen J, Kero P, Valimaki I: Reactivity of skin blood flow and heart rate to thermal stimulation in infants during the first postnatal days and after a two-month follow-up. Acta Paediatr 1996 85:733-738.

53. Genzel-Boroviczeny O, Strotgen J, Harris AG, Messmer K, Christ F: Orthogonal polarization spectral imaging (OPS): a novel method to measure the microcirculation in term and preterm infants transcutaneously. Pediatr Res 2002, 51:386-391.

54. Genzel-Boroviczeny O, Christ F, Glas V: Blood transfusion increases functional capillary density in the skin of anemic preterm infants. Pediatr Res 2004, 56:751-755.

55. Kroth J, Weidlich K, Hiedl S, Nussbaum C, Christ F, Genzel-boroviczeny O: Functional vessel density in the first month of life in preterm neonates. Pediatr Res 2008, 64:567-571.

56. Hiedl S, Schwepcke A, Weber F, Genzel-Boroviczeny O: Microcirculation in preterm infants: profound effects of patent ductus arteriosus. J Pediatr 2010, 156:191-196.

57. Top AP, Ince C, van Dijk M, Tibboel D: Changes in buccal microcirculation following extracorporeal membrane oxygenation in term neonates with severe respiratory failure. Crit Care Med 2009, 37:1121-1124.

58. Weidlich K, Kroth J, Nussbaum C, Hiedl S, Bauer A, Christ F, GenzelBoroviczeny O: Changes in microcirculation as early markers for infection in preterm infants-an observational prospective study. Pediatr Res 2009, 66:461-465.

59. Top AP, Ince C, de Meij N, van Dijk M, Tibboel D: Persistent low microcirculatory vessel density in non-survivors of sepsis in pediatric intensive care. Crit Care Med 2011, 39:8-13.

60. Top AP, Ince C, Schouwenberg PH, Tibboel D: Inhaled nitric oxide improves systemic microcirculation in infants with hypoxemic respiratory failure. Pediatr Crit Care Med, in press.

61. Perera P, Kurban K, Ryan TJ: The development of the cutaneous microvascular system in the newborn. Br J Dermatology 1970, 82 (S5):86-91.

62. Stopfkuchen $\mathrm{H}$ : Changes of the cardiovascular system during the perinatal period. Eur J Pediatr 1987, 146:545-549.

63. Trzeciak S, McCoy JV, Dellinger RP, et al.: Early increases in microcirculatory perfusion during protocol-directed resuscitation are associated with reduced multi-organ failure at $24 \mathrm{~h}$ in patients with sepsis. Intensive Care Med 2008, 34:2210-2217.

64. De Backer D, Creteur J, Dubois MJ, Sakr Y, Vincent JL: Microvascular alterations in patients with acute severe heart failure and cardiogenic shock. Am Heart J 2004, 147:91-99.

65. Jhanji S, Lee C, Watson D, Hinds C, Pearse RM: Microvascular flow and tissue oxygenation after major abdominal surgery: association with postoperative complications. Intensive Care Med 2009, 35:671-677.

doi:10.1186/cc9995

Cite this article as: Top APC, et al:: The microcirculation of the critically ill pediatric patient. Critical Care 2011, 15:213. 